\title{
Development of Conduct Problems and Peer Rejection in Preschool Children: A Social Systems Analysis
}

\author{
Sheryl L. Olson ${ }^{1,2}$
}

The development of impulsive-aggressive problem behavior and peer rejection was examined in sixty 4- to 5-year-old boys from low-income family backgrounds. Children's sociometric status and behavioral adjustment were assessed longitudinally at the beginning and end of the preschool year, and related to measures of peer interaction at three different points in time. Boys identified as socially rejected and aggressive in the beginning of the year were highly likely to be identified as such at the end of the year. Early in the preschool year, these children contributed to their own rejection by initiating socially aversive exchanges with peers. Although peers clearly perceived these problems, they did not reciprocate with counteraggression at first. However, as time passed, peers began to actively victimize these children, and most of the aggression on the part of victims became reactive in nature. Thus, the current findings strongly support a transactional model of the development of early peer rejection and conduct problems.

The goal of this study was to elucidate the role of the preschool peer system in the development of early conduct problems. A growing body of research has shown that school-age boys with conduct problems such as aggression and impulsivity are at elevated risk for peer rejection (e.g., Asher \& Dodge,

Manuscript received in final form August 8, 1991.

The author is indebted to the Head Start teachers, children, and parents who participated, and to the following individuals for their invaluable help with data collection and coding: Margo Bonner, Beth O'Connell, Cindy Friedman, Elizabeth Jamner, Karen Lifgren, Marina Post, Jacqueline Raznick, Lisa Walsh, and Karen Weitzner.

${ }^{1}$ University of Michigan, Ann Arbor, Michigan 48109.

${ }^{2}$ Address all correspondence to S. L. Olson, Department of Psychology, University of Michigan, 580 Union Drive, Ann Arbor, Michigan 48109. 
1986; Cantrell \& Prinz, 1985; Carlson, Lahey, \& Neeper, 1984; Coie \& Dodge, 1983; Milich \& Landau, 1982). Examining the developmental origins of these problems is a compelling research issue because both childhood conduct problems and peer rejection are predictive of social maladjustment in later life (see Parker \& Asher, 1987). However, we know comparatively little about the development of peer rejection and conduct problems in preschool children. Behavior problems of preschool children have often been viewed as ephemeral, but stable individual differences in aggression have been demonstrated in preschool-age boys (Olweus, 1979). For example, aggressive problem behavior identified as early as 2 years of age has been found to persist across a 3- to 4-year time span (Campbell, Breaux, Ewing, \& Szumowski, 1986; Cummings, Iannotti, and Zahn-Waxler, 1989; Rose, Rose, \& Feldman, 1989). Finally, several investigators have reported that conduct problems and peer rejection tend to co-occur in preschool children (Millich, Landau, Kilby, \& Whitten, 1982; Olson \& Lifgren, 1988; Rubin \& Clark, 1983).

In short, convergent evidence from many different sources indicates that serious conduct problems do occur in preschool-age children, and that these problems are associated with impaired peer relations. Closer examination of the peer context of early conduct problems has relevance for early intervention, and for understanding how the association between behavior problems and peer rejection develops over time.

In the current study, the development of impulsive-aggressive problem behavior and peer rejection was examined in a risk sample of preschoolers. A social systems framework was adopted, focusing on transactional sequences of peer interaction which potentially exacerbate and maintain patterns of social maladjustment in young children. Although social systems conceptualizations have been underutilized in research on peer rejection, several studies have suggested the potential usefulness of such an approach. Some investigators have found that rejected children tend to be negatively stereotyped in ways which distort their actual level of disruptiveness in peer group situations (Campbell \& Yarrow, 1961; Coie \& Kuperschmidt, 1983). For example, Coie and Kuperschmidt reported that boys in both familiar and unfamiliar play groups viewed rejected boys as the ones most likely to start fights, but these boys were no more likely than others to initiate physical assaults. Other investigators have pointed out that acts of peer aggression may have vastly different implications for children's social adjustment, depending upon the context and sequencing of the aggressive behavior. For example, Dodge and Coie (1987) proposed that there are two qualitatively different types of childhood aggression, with different implications for risk status. Proactive-instrumental aggression, characterized by coercion and bullying with no immediate provocation, may 
co-exist with peer popularity. That is, instrumental bullying may enhance the child's status in his peer group, or at the very least not impair it. By contrast, reactive aggression, characterized by aggressive responses to hostile provocation, is closely associated with peer rejection. Similarly, Asarnow (1983) found that when socially rejected boys became involved in negative peer exchanges, they were likely to continue in a negative manner. This self-perpetuating "cycling" effect did not characterize the negative interactions of nonrejected boys. Thus, careful attention must be given to the immediate social context of aggressive behavior, distinguishing between functionally different types of aggressive exchanges. These studies also indicate the potential importance of negative peer perceptions as maintaining factors in reactive forms of aggressive maladjustment.

On the other hand, children are not randomly selected for peer rejection. Studies of children placed in unfamiliar play groups indicate that some behave in ways which invite rejection. For example, Dodge (1983) found that rejected boys in novel play groups showed a broad range of aversive interpersonal behaviors, including irritating mannerisms, inappropriate play, hostile verbalizations, exclusion of peers, and hitting. Coie and Kuperschmidt (1983) also placed school-age boys in unfamiliar play groups. By the end of the third week of group meetings, "rejected" status in unfamiliar groups was as highly correlated with actual school status as in later meetings. Finally, in a study of normal preschoolers, Ladd, Price, and Hart (1988) found that children's early social behaviors (e.g., argumentativeness; extent of cooperative play) were the best predictors of peer status assessed at the end of the year. Clearly, children's behavioral styles contribute to the development of rejection by peers. There is a need to distinguish between the initial development of peer rejection and factors related to its maintenance.

These combined studies suggest that a transactional, social systems model is needed to explain the development and co-occurrence of early conduct problems and peer rejection. The following components of such a model are tentatively proposed. First, during the initial formation phase, some children enter peer groups with impaired social skills which place them at risk for being negatively perceived by playmates. Although disruptiveness and aggressive responses to conflict are obvious examples of behaviors which elicit negative reactions from peers (Dodge, 1983), other possibilities include argumentativeness and high rates of conflict participation (Ladd et al., 1989; Shantz, 1986). The second phase involves interpersonal processes leading to the stabilization of negative peer transactions. Once negative reputations become somewhat established, peers begin to provoke aggressive reactions from rejectees. Thus, peer situations become charged with a great deal of negative emotionality, and chances to learn 
alternative, proactive social skills are greatly reduced. Finally, at this transactional cycle progresses, children begin to internalize their peers' negative views of them and may perceive even relatively benign social situations as potential threats to self-esteem (e.g., Dodge, Murphy, \& Buchsbaum, 1984). All of these factors, either alone or in combination, could account for longterm continuity in social maladjustment.

\section{Objective of Current Study}

A short-term longitudinal design was used to test several aspects of this model with children beginning preschool. Children's sociometric status and behavioral adjustment were assessed at the beginning and end of the preschool year, and related to measures of peer interaction behavior assessed at different points in time. Consistent with the findings of Coie and Kuperschmidt (1983), it was expected that individual differences in negative ("rejected") social status would emerge relatively quickly (i.e., within the first 2 months of preschool) and remain at least moderately stable over the course of the preschool year. Furthermore, it was expected that peer rejection would be correlated with the presence of conduct problems and with patterns of negative (e.g., aggressive, coercive) peer interaction. Finally, it was hypothesized that peers would actively contribute to the maintenance of these behavior problems by provoking negative emotional reactions from rejectees.

This study was intended to contribute to the existing literature in several ways. The early development and co-occurrence of peer rejection and conduct problems is an understudied problem with great relevance to children's social risk status. Longitudinal assessments permitted the identification of specific patterns of social behavior predictive of social maladjustment in the eyes of peers and teachers, and provided information about when these patterns become established during the preschool year. Finally, subjects in the current study shared two characteristics that have been independently related to elevated rates of early childhood conduct problems: male sex (Crowther, Bond, \& Rolf, 1981) and low-income family status (Rutter \& Garmezy, 1983). Although this sample was chosen with the expectation of finding relatively high rates of externalizing problems, it also allowed for the identification of individual differences in social competence within this risk group. Information bearing on the latter question may be quite useful in the development of early identification and intervention programs for young children at elevated risk for social maladjustment. 


\section{METHOD}

\section{Subjects}

Subjects were sixty 4 - to 5 -year old boys ( $M=4$ years, 6 months; range $=4.0$ to 5.5 years) from low-income families. These boys were drawn from eight Head Start preschool classes, serving a total of 96 boys and girls. The racial composition of the classes was homogeneous (98\% white). Classes extended from late September through mid-May of the following year. Written parental consent and verbal child assent were obtained for all participants; no parent or child refused participation. Therefore, every boy in each classroom was targeted as a subject. Subjects were free of severe physical and mental disabilities.

\section{Procedures}

Overview. The design of this study involved assessing peer and teacher perceptions of children's behavioral maladjustment in the fall (late October) and spring (April) of the preschool year, and linking these measures to repeated observations of children's social transactions. Teacher and peer assessments were conducted during the same time periods, which generally co-occurred with the first and final series of behavioral observations (all were conducted within a month of the teacher and peer assessments). The second set of observations occurred in January and February, midway between the first and third. Although the basic $N$ was $60, N \mathrm{~s}$ for specific measures fluctuated from 52 to 60 due to missing data.

Assessment of Peer Interaction. During the end of the second month of preschool classes, children were brought to a $10 \times 15$-foot play area outside their preschool classrooms. A variety of age-appropriate toys were placed in the center of the observation area, including puppets, toy cars, wooden building blocks, toy dinosaurs, and a large motorized spaceship with flashing lights. Children who attended the same preschool class were videotaped in play groups of five (three boys and two girls) over a 5-month time span. During each play session, one boy was marked as the primary target of observation, and was followed at all times with the camera. The four peers were chosen randomly from each classroom. Prior to taping children were asked to play together as they normally would; after several minutes of warmup, $10 \mathrm{~min}$ of play interaction were recorded. Observations were repeated in the winter and late spring, so that every boy in the study was targeted on three different occasions. The length of time between observations was kept relatively constant for all target subjects. 
Verbal and nonverbal interactions involving target children were transcribed from the tapes and ordered according to initiation and response sequences. An initiation was defined as social behavior which has not been preceded by another social contact within the last $5 \mathrm{sec}$ (Leiter, 1977). All social initiations made by the target child to peers or by peers to the target were recorded in the first column, as the beginning of a sequence. The second column contained the entire sream of responses and counterresponses involved in the sequence, distinguishing between contributions of targets versus those of specific peers. Sequences usually terminated when one child left to pursue another activity. The following measures were taken to ensure the reliability of the transcripts. Transcribers were trained to describe behavioral sequences in ways which required as little inference as possible. They initially practiced on five separate observations, until perfect or near-perfect (95-100\%) agreement was achieved for separate initiation and response sequences. Disagreements were decided by a third person, usually the author. Twenty transcripts were independently transcribed and checked, resulting in consistently high levels of agreement ( $95 \%$ or above). Finally, to guard against "transcriber drift," transcripts of 20 additional observations were checked periodically by at least one other individual.

A 20-category behavioral coding system was developed, encompassing a broad range of positive and negative behaviors. Individual codes, shown in Table I, represented the following higher-order categories: social conversation, cooperative play, conflict-relevant verbal behavior, helpful or affectionate behavior, assertive behavior, and coercive-aggressive behavior. Transcripts were coded by three individuals who were blind to other information about children's social adjustment. One person, different from the transcriber, was designated as primary coder for a given set of transcripts. A second individual served as checker. One hundred twenty transcripts were randomly selected for checking. Due to differences in base rates, intercoder reliabilities were calculated for each different behavior category using the following formula: number of agreements/number of disagreements plus agreements $\times 100$. Intercoder reliabilities were high, ranging from $79-100 \%$ for individual codes $(M=89 \%)$. Cohen's kappa, a more conservative estimate of reliability that corrects for chance agreement, was also used to check intercoder reliabilities. All kappas were acceptable, ranging from .54 to 1.00 with a mean of .80 . Reliability coefficients for individual codes are shown in Table I.

Base rates for behavioral categories used in data analyses are shown in Table II. Because negative social behaviors were a central part of the study, they are listed individually as well as by aggregated higher-order categories. Although base rates for most forms of aggression were low, rates 
Table I. Examples of Individual Peer Interaction Behavior Codes

Social conversation

Declarative statement $(91 \% ; \kappa=.68)$. Neutral statements about objects or activities; no conflict or need implied (e.g., "I like the blue one").

Request/need statement $(90 \% ; \kappa=.85)$. Examples: "Can I play with your spaceship?" "I need that block."

Suggest activity (87\%; $\mathrm{k}=.78)$. Examples: "Want to play with my car?" "Let's do this." Request for information $(90 \% ; \kappa=.76)$ ). Example: "What are you building?"

\section{Cooperative play}

Play talk/noises $(80 \% ; \kappa=.76)$. Friendly verbal play interactions (examples: "Zoom, zoom, zoom"; "My monster is going to get you!"; friendly singing).

Nonverbal play behavior $(95 \% ; \kappa=.54)$. Friendly attempts to initiate play or respond to play with nonverbal gestures.

\section{Conflict-relevant verbal behavior}

Refusal $(86 \% ; \kappa=.80)$. Example: "No, I don't want to."

Verbal argument $(92 \% ; \mathrm{x}=.89)$. Gives reasons for not complying with requests or demands (example: "No, its my turn to play"); verbal contradiction; gives reasons for wanting disputed object.

\section{Assertive behavior}

Directive verbal $(89 \% ; \kappa=.56)$. Demands (e.g., "Give me that truck") or commands ("Stop that!").

Verbal protest $(85 \% ; \kappa=.83)$. Protests specific behaviors of peers; not aggressive (e.g." "You're blocking me!").

\section{Affection and helping}

Demonstrate affection $(100 \% ; \kappa=.98)$. Physical affection (hug, kiss, tender touch) or verbal praise.

Helping $(96 \% ; \kappa=95)$. Offers instrumental or emotional support to child in need.

\section{Verbal aggression}

Threat $(96 \% ; \kappa=.94)$. Threatens physical harm (verbal or nonverbal).

Verbal abuse $(87 \% ; \kappa=.85)$. Insults, taunts, or derogates.

\section{Physical coercion-aggression}

Object aggression $(95 \% ; \kappa=.75)$. Throws or strikes other children's toys or play materials, e.g., intentional destruction of block tower that other children have constructed.

Grabs object $(92 \% ; \kappa=.60)$. Grabs an object away from peer.

Annoying behavior $(89 \% ; \kappa=86)$. Annoying low level provocations such as tapping on a child's head, mild pushing away, or physically grabbing another child. No clear intent to inflict harm.

Physical aggression $(97 \% ; \kappa=95)$. Shoves, hits, scratches, bites, or kicks peer; clear intent to inflict harm.

Fantasy aggression $(87 \% ; \kappa=83)$. Acts of physical aggression carried out in fantasy role; e.g., enactment of violent battle between two "spacemen."

\section{Other}

Ignore peer $(93 \% ; \kappa=.90)$. Ignores initiations or responses of peer. 
Table II. Means and Standard Deviations for Behavioral Codes

\begin{tabular}{|c|c|c|c|c|c|c|}
\hline \multirow[b]{2}{*}{ Behavioral category } & \multicolumn{2}{|c|}{ Time 1} & \multicolumn{2}{|c|}{ Time 2} & \multicolumn{2}{|c|}{ Time 3} \\
\hline & $M$ & $S D$ & $M$ & $S D$ & $M$ & $S D$ \\
\hline Social conversation & 5.8 & 4.3 & 7.85 & 5.85 & 7.66 & 6.22 \\
\hline Cooperative play & 8.48 & 6.9 & 8.08 & 5.43 & 4.24 & 2.74 \\
\hline Verbal conflict & 4.23 & 4.14 & 3.45 & 2.94 & 3.14 & 2.78 \\
\hline Affection & 1.94 & 2.15 & 0.41 & 1.26 & 0.28 & 0.81 \\
\hline Ignore & 3.25 & 2.46 & 1.83 & 1.34 & 2.70 & 2.15 \\
\hline Assertive behavior & 4.26 & 3.99 & 5.75 & 5.71 & 5.50 & 4.55 \\
\hline Verbal aggression (total) & 0.80 & 1.51 & 0.68 & 1.43 & 1.06 & 1.80 \\
\hline Threat & 0.26 & 0.71 & 0.37 & 0.86 & 0.50 & 1.07 \\
\hline Verbal abuse & 0.53 & 1.11 & 0.31 & 0.72 & 0.56 & 1.07 \\
\hline Physical aggression (total) & 4.13 & 4.48 & 3.31 & 3.01 & 5.42 & 6.26 \\
\hline Direct physical & 0.17 & 0.47 & 0.31 & 0.82 & 0.84 & 2.06 \\
\hline Annoying behavior & 0.86 & 1.35 & 0.64 & 1.00 & 1.18 & 2.29 \\
\hline Object aggression & 3.26 & 4.36 & 2.95 & 3.79 & 3.42 & 4.17 \\
\hline Grab object & 3.15 & 3.50 & 1.95 & 1.67 & 3.18 & 2.90 \\
\hline Fantasy aggression & 0.92 & 2.03 & 0.70 & 1.45 & 0.32 & 0.58 \\
\hline
\end{tabular}

of object-oriented aggression (grabbing toy away from peer; smashing or throwing toys) were relatively high.

Behavior Problem Ratings. During the fall, teachers completed the Conners Teacher Questionnaire (Goyette, Conners, \& Ulrich, 1978). This version of the questionnaire consisted of thirty-three 4-point scales, on which the presence of specific problems were rated $(1=$ not at all a problem, $4=$ very much a problem). The two major questionnaire scales were Conduct Problems (acts impudent, temper outbursts, hypersensitive to criticism, sulks, mood changes quickly, uncooperative with teacher, aggressive) and Hyperactivity (restless, makes inappropriate noises; disturbs other children, constantly on the go, impulsive and excitable, makes excessive demands on teacher's attention). The Conners questionnaires were again completed during the late spring. Not surprisingly, the Conduct Problems and Hyperactivity scales were highly intercorrelated: $r=.75, p<.0001$, at Time 1, and $r=.83, p<.0001$, at Time 2. Therefore, in the interests of data reduction, these two scales were composited. Estimates of internal consistency for the scales, computed using Chronbach's alpha, were as follows: .94 at Time 1, and .93 at Time 2. Means and standard deviations for each composite scale were: $M=23.66, S D=8.56$, at Time 1 , and $M=$ $22.50, S D=13.27$, at Time 2 .

Assessment of Peer Status. During the fall, all boys and girls in each classroom participated in individual peer sociometric interviews. After identifying self and classmates from a picture array, each child was asked to 
nominate two classmates s/he most liked to play with, then two classmates s/he least liked to play with. ${ }^{3}$ In order to obtain more highly qualitative information about children's peer perceptions, children were also asked to nominate two classmates who best fit the following behavioral descriptors (adapted from Milich et al., 1982): Who is mean? Who fights, hits, and punches a lot? Who runs around the room a lot? Who gets mad easily? Who can't sit still? Who doesn't listen? Total scores on each variable were tallied for each boy in the study, then standardized to correct for small variations in class sizes. All peer sociometric assessment procedures were repeated during the late spring.

The following peer sociometric measures were used in data analyses: number of negative nominations received from peers at each time period $(M=1.7, S D=1.7$, at Time $1 ; M=1.9, S D=1.8$, at Time 2$)$, and number of total behavior problem nominations received from peers at each time period $(M=6.8, S D=4.7$, at Time $1 ; M=8.8, S D=6.6$, at Time 2). Estimates of internal consistency, computed using Chronbach's alpha, were as follows for the behavior problem nomination scales: .73 at Time 1 , and .82 at Time 2 .

\section{RESULTS}

\section{Intercorrelations Between Teacher and Peer Measures of Maladjustment}

It was expected that measures of peer rejection and conduct problems would co-occur, and show significant levels of stability over the course of the preschool year. These hypotheses were strongly confirmed. As shown in Table III, measures of peer rejection and impulsive-aggressive problem behavior were moderately highly intercorrelated, both within and between time periods. Individual differences in negative peer status were moderately stable over time, and peer and teacher measures of aggressive and impulsive behavior problems showed high temporal stability.

\section{Overall Peer Interaction Correlates of Social Maladjustment}

Measures of peer interaction behavior were summed across time periods and intercorrelated with measures of negative peer status and conduct problems at both assessment points. Due to the relatively large number of

\footnotetext{
${ }^{3}$ Although it is conventional to require three sociometric choices in each category, two choices were obtained in the present study due to the small class sizes (average $=10$ children per class).
} 
Table III. Correlations Between Peer and Teacher Measures of Social Maladjustment $^{a}$

\begin{tabular}{cccccccc}
\hline & \multicolumn{3}{c}{ Time 1 } & & \multicolumn{3}{c}{ Time 2 } \\
\cline { 2 - 4 } \cline { 6 - 7 } \cline { 5 - 7 } & TCON & PNEG & PAGG & & TCON & PNEG & PAGG \\
\hline Time 1 & 1.00 & $0.28^{b}$ & $0.51^{b}$ & & $0.80^{c}$ & $0.37^{d}$ & $0.57^{c}$ \\
TCON & & 1.00 & $0.57^{d}$ & & $0.25^{b}$ & $0.44^{d}$ & $0.28^{b}$ \\
PNEG & & & 1.00 & & $0.58^{c}$ & $0.61^{c}$ & $0.76^{c}$ \\
PAGG & & & & & & & \\
Time 2 & & & & & & & \\
TCON & & & & & 1.00 & $0.39^{d}$ & $0.61^{c}$ \\
PNEG & & & & & 1.00 & $0.71^{c}$ \\
PAGG & & & & & & 1.00 \\
\hline
\end{tabular}

${ }^{a} N \mathrm{~s}=52-57 ; \mathrm{TCON}=$ Conduct Problems, Conners Teacher Questionnaire; PNEG = negative peer nominations; $\mathrm{PAGG}=$ peer nominations of impulsive-aggressive behavior.

$b_{p}<.05$.
$c_{p}<.001$
$d_{p}<.01$.

variables, Bonferroni's correction was used to control for spurious correlations resulting from "familywise" error rates. First, I questioned whether children who were perceived as maladjusted by teachers and peers might show higher rates of aversive social behavior than others. As shown in Table IV, relatively few categories of social initiation behaviors on the part of the target children were significantly related to their maladjustment scores. However, the overall rate of coercive-aggression initiations to peers was associated with peer perceptions of dislikability and aggressiveness at both time periods, and with teacher's ratings of conduct problems at the end of the year. Similarly, negative responses of target children to peers were consistently correlated with measures of social maladjustment. Children who were perceived by teachers and peers as behaviorally deviant tended to respond to their peers' behaviors with relatively high rates of verbal and physical aggression. This pattern also characterized children who were disliked by their peers at Time 2 . Thus, as expected, aversive social behaviors on the part of target children were most clearly associated with individual differences in their levels of social maladjustment. Other categories of social behavior, such as cooperative play, conflict participation, or social conversation, were either unrelated or negligibly related to maladjustment.

As shown in Table V, children who were disliked and perceived by peers as aggressive tended to receive relatively high rates of verbally and physically aggressive peer initiations, as did children who received high teacher ratings of behavior problems at Time 2. Children who were perceived as aggressive by peers also received higher rates of verbally assertive initiations from peers (e.g., commands or demands) than others. Finally, 
Table IV. Correlations Between Target Initiations/Responses to Peers and Measures of Social Maladjustment in Target Children ${ }^{a}$

\begin{tabular}{lccccccc}
\hline & \multicolumn{3}{c}{ Fall } & & \multicolumn{3}{c}{ Spring } \\
\cline { 2 - 3 } \cline { 6 - 8 } \cline { 6 - 8 } & TCON & PNEG & PAGG & & TCON & PNEG & PAGG \\
\hline Target initiations & & & & & & & \\
Social conversation & .03 & .03 & .16 & & .00 & .18 & $.30^{a}$ \\
Cooperative play & .15 & .20 & $.26^{b}$ & & .02 & .19 & .10 \\
Affection & .05 & .10 & .01 & & .02 & .10 & .01 \\
Assertive behavior & .04 & .13 & .12 & & .02 & .10 & .13 \\
Verbal aggression & .19 & .08 & .06 & & $.29^{b}$ & .15 & .16 \\
Physical aggression & .21 & $.25^{b}$ & $.35^{b}$ & & $.29^{b}$ & $.25^{b}$ & $.34^{b}$ \\
Target responses & & & & & & & \\
Social conversation & .12 & .12 & .21 & & .24 & .23 & .22 \\
Cooperative play & .08 & $.28^{b}$ & .12 & & .18 & .11 & .01 \\
Conflict talk & .33 & .02 & .00 & & .22 & .22 & .04 \\
Affection & .21 & .10 & .06 & & .05 & .17 & .10 \\
Assertive behavior & .21 & .21 & .19 & & .24 & .24 & .19 \\
Verbal aggression & $.30^{b}$ & .19 & $.48^{c}$ & & $.24^{b}$ & $.48^{c}$ & $.50^{d}$ \\
Physical aggression & $.34^{b}$ & $.29^{b}$ & $.40^{c}$ & & $.37^{c}$ & $.30^{b}$ & $.46^{c}$ \\
lgnore & $.29^{b}$ & .20 & .08 & & $.36^{b}$ & .00 & .11 \\
\hline
\end{tabular}

$\overline{a_{\text {TCON }}=\text { Conduct Problems, Conners Teacher Questionnaire; PNEG }=\text { negative peer }}$ nominations; $\mathrm{PAGG}=$ peer nominations of impulsive-aggressive behavior.

$b_{p}<.05$.

$c_{p}<.01$.

$a_{p}<.001$.

children perceived negatively by peers tended to receive more verbally aggressive peer responses than others, as well as relatively high rates of nonaggressive verbal exchanges. The latter association suggests that disliked and aggressive children have high social salience in the preschool classroom.

In summary, the peer interaction correlates of individual differences in social maladjustment were consistently patterned. Coercive-aggressive behaviors were more frequently associated with measures of peer rejection and impulsive-aggressive problem behavior than other measures of social interaction. Furthermore, children perceived by peers as disliked and disruptive tended to deliver and receive higher rates of aggression than others, suggesting that both target children and peers actively contributed to the maintenance of these negative interactive patterns. In order to better understand the meaning of these patterns, further data analyses focused on two questions. First, the two aggression scales (verbal and physical) encompassed a broad range of socially aversive behaviors. Therefore, which specific types of coercive and/or aggressive behaviors were most highly predictive of children's social maladjustment scores? Second, at what point in time do patterns of negative peer interaction become predictive of negative social outcomes? 
Table V. Correlations Between Peer Initiations/Responses to Target and Measures of Social Maladjustment in Target Children ${ }^{a}$

\begin{tabular}{llllllll}
\hline & \multicolumn{3}{c}{ Fall } & & \multicolumn{3}{c}{ Spring } \\
\cline { 2 - 3 } \cline { 6 - 8 } \cline { 6 - 8 } & TCON & PNEG & PAGG & & TCON & PNEG & PAGG \\
\hline Peer initiations & & & & & & & \\
Social conversation & .05 & .06 & .03 & & .04 & $.32^{b}$ & .09 \\
Cooperative play & .00 & $.28^{b}$ & .08 & & .16 & .22 & .04 \\
Affection & .04 & .13 & .18 & & .00 & .17 & -.17 \\
Assertive behavior & .00 & .04 & $.25^{b}$ & & .02 & $.31^{b}$ & $.28^{b}$ \\
Verbal aggression & .22 & $.29^{b}$ & $.28^{b}$ & & $.40^{c}$ & $.35^{b}$ & .21 \\
Physical aggression & .04 & $.34^{b}$ & $.43^{c}$ & & .08 & .19 & $.26^{b}$ \\
Peer responses & & & & & & & \\
Social conversation & .05 & .01 & $.28^{b}$ & & .15 & $.28^{b}$ & $.35^{b}$ \\
Cooperative play & .02 & .18 & .13 & & .03 & .13 & .12 \\
Conflict lalk & .09 & .20 & .09 & & .13 & .22 & .15 \\
Affection & .13 & .07 & .16 & & .09 & .04 & .08 \\
Assertive behavior & .07 & .01 & .07 & & .03 & .01 & .09 \\
Verbal aggression & .06 & .17 & $.35^{c}$ & & .13 & $.32^{b}$ & $.30^{b}$ \\
Physical aggression & .04 & .15 & .22 & & .13 & $.30^{b}$ & .19 \\
Ignore & $.37^{c}$ & $.25^{b}$ & $.27^{b}$ & & $.36^{c}$ & $.29^{b}$ & $.27^{b}$ \\
\hline
\end{tabular}

${ }^{a}$ TCON = Conduct Problems, Conners Teacher Questionnaire; PNEG = negative peer nominations; PAGG = peer nominations of impulsive-aggressive behavior.

$b_{p}<.05$.

$c_{p}<.01$

\section{Specific Negative Behavioral Correlates of Social Maladjustment}

Are certain types of coercive or aggressive behavior more highly correlated with children's social maladjustment levels than others? First, negative initiation behaviors of target children such as physical assaults (hitting, pushing, shoving, kicking, biting), threats, verbal insults, object-centered aggression, and fantasy play aggression were intercorrelated with peer and teacher measures of rejection and conduct problems at both time periods. As shown in Table VI, children who were perceived as maladjusted by peers tended to initiate more aggressive social exchanges than others, including physical and verbal assaults, grabbing objects away, and smashing or hurling play materials.

Negative responses of target children to peers were also consistently correlated with their levels of social maladjustment. Children rated highly on all maladjustment scales tended to react to peer behaviors with a broad range of aversive responses, including physical assaults, verbal threats and insults, object-centered aggression, fantasy aggression, and annoying behavior.

Next, patterns of negative peer initiations and responses to target children were examined as correlates of social maladjustment in these children. As shown in Table VII, peers tended to address children rated highly on all maladjustment scales in provocatively negative ways, i.e., with verbal insults and threats. More- 
Table VI. Correlations between Specific Negative Target Initiations/Responses to Peers and Measures of Target Child Maladjustment ${ }^{a}$

\begin{tabular}{llllllll}
\hline & \multicolumn{3}{c}{ Fall } & & \multicolumn{3}{c}{ Spring } \\
\cline { 2 - 5 } \cline { 6 - 8 } \cline { 6 - 8 } & TCON & PNEG & PAGG & & TCON & PNEG & PAGG \\
\hline $\begin{array}{llllllll}\text { Target initiations to peers } \\
\text { Physical aggression }\end{array}$ & $.27^{b}$ & $.29^{b}$ & $.26^{b}$ & & .13 & $.27^{b}$ & .16 \\
Threat & .18 & .09 & .00 & & .16 & .03 & .05 \\
Verbal abuse & .11 & .02 & .11 & & .08 & $.36^{b}$ & $.25^{b}$ \\
Object aggression & .18 & .19 & $.30^{b}$ & & $.29^{b}$ & .20 & $.28^{b}$ \\
Grab object & .08 & .06 & .16 & & .11 & $.36^{b}$ & $.35^{b}$ \\
Annoying behavior & .16 & .00 & .17 & & .08 & .07 & $.25^{b}$ \\
Target responses to peers & & & & & & & \\
Physical aggression & $.43^{c}$ & .16 & $.56^{d}$ & & $.42^{c}$ & $.31^{b}$ & $.57^{d}$ \\
Threat & $.24^{b}$ & $.29^{b}$ & $.58^{d}$ & & .17 & $.56^{d}$ & $.58^{d}$ \\
Verbal abuse & $.29^{b}$ & .00 & .17 & & $.29^{b}$ & .21 & .22 \\
Object aggression & $.26^{b}$ & .05 & .13 & & $.28^{b}$ & .02 & .13 \\
Grab object & .03 & $.34^{b}$ & .13 & & .19 & $.35^{b}$ & $.27^{b}$ \\
Fantasy aggression & $.43^{c}$ & $.38^{c}$ & $.51^{d}$ & & $.39^{c}$ & $.53^{d}$ & $.49^{d}$ \\
Annoying behavior & .15 & .09 & .03 & & .00 & $.33^{b}$ & $.37^{b}$ \\
\hline
\end{tabular}

${ }^{a}$ TCON $=$ Conduct Problems, Conners Teacher Questionnaire; PNEG = negative peer nominations; PAGG = peer nominations of impulsive-aggressive behavior.

$b_{p}<.05$.

$c_{p}<.01$.

$p<.001$.

over, peers tended to initiate physical assaults on children who received high rejection and behavior problem nominations, and to respond to these children with relatively high rates of physical and object centered aggression. However, patterns of peer responses to target children were unrelated to teachers' evaluations of the targets' behavioral maladjustment levels.

In summary, children who were perceived by their peers as disliked and disruptive tended to initiate and respond to peers with a broad range of aversive social behaviors. Moreover, peers appeared to play an active role in the maintenance of social maladjustment in these children, by insulting, threatening, and physically assaulting them.

\section{Temporal Sequencing of Relationships Between Negative Peer Interaction and Social Maladjustment}

Prior analyses have indicated that patterns of coercive-aggressive peer interaction were the most consistent behavioral correlates of social maladjustment in young at-risk children. At what point in time during the preschool year do negative social transactions become associated with peer rejection and/or conduct problems? In order to address this question, rates 
Table VII. Correlations Between Specific Negative Peer Initiations/Responses to Target and Measures of Target Maladjustment ${ }^{a}$

\begin{tabular}{|c|c|c|c|c|c|c|}
\hline & \multicolumn{3}{|c|}{ Fall } & \multicolumn{3}{|c|}{ Spring } \\
\hline & TCON & PNEG & PAGG & TCON & PNEG & PAGG \\
\hline \multicolumn{7}{|c|}{ Peer initiations to target } \\
\hline Physical aggression & .21 & $.26^{c}$ & $.53^{b}$ & .20 & $.28^{c}$ & $.40^{d}$ \\
\hline Threat & .15 & .19 & .16 & $.30^{\mathrm{c}}$ & $.29^{c}$ & .16 \\
\hline Verbal abuse & $.29^{c}$ & $.37^{c}$ & $.35^{c}$ & $.46^{b}$ & $.38^{d}$ & $.25^{c}$ \\
\hline Object aggression & .02 & .22 & $.27^{c}$ & .08 & .04 & .12 \\
\hline Grab object & .00 & .00 & .03 & .03 & .09 & .12 \\
\hline Fantasy aggression & $.24^{\mathrm{c}}$ & .21 & .01 & .18 & .17 & .05 \\
\hline Annoying behavior & .06 & .00 & $.32^{c}$ & .05 & .00 & $.26^{c}$ \\
\hline \multicolumn{7}{|c|}{ Peer responses to target } \\
\hline Physical aggression & .08 & .01 & .06 & .22 & $.38^{d}$ & $.25^{c}$ \\
\hline Threat & .05 & .22 & $.33^{c}$ & .07 & $.33^{\mathfrak{c}}$ & .19 \\
\hline Verbal abuse & .02 & .15 & $.26^{\mathfrak{C}}$ & .09 & $.30^{c}$ & .20 \\
\hline Object aggression & .14 & .01 & .10 & .01 & .07 & .00 \\
\hline Grab object & .09 & .10 & .22 & .19 & $.37^{d}$ & $.31^{c}$ \\
\hline Fantasy aggression & .18 & .10 & .05 & .11 & .10 & .05 \\
\hline Annoying behavior & .08 & .22 & $.32^{c}$ & .08 & .06 & .12 \\
\hline
\end{tabular}

${ }^{a}$ TCON = Conduct Problems, Conners Teacher Questionnaire; PNEG = negative peer nominations; PAGG = peer nominations of impulsive-aggressive behavior.

$b_{p}<.001$.

$c_{p}<.05$.

${ }_{p}<.01$

of verbal and physical aggression within each different observation period were separately intercorrelated with measures of peer rejection and conduct problems. As shown in Table VIII, during the first and second observation periods, aggressive initiations/responses of target children to peers were unrelated to their behavioral maladjustment levels as rated by teachers, but somewhat associated with dislike and behavior problem nominations from peers. Children who received high peer rejection and behavior problem scores, both at the beginning and end of preschool, tended to make frequent verbally aggressive initiations to peers, and tended to respond more aggressively to peer initiations than others. During the final observation period, aggressive initiations and responses on the part of target children were associated with teacher's ratings of behavioral maladjustment as well.

Patterns of aggressive peer initiations/responses to target children showed striking differences in their associations with measures of maladjustment in the target children, depending on time of observation. As shown in Table IX, during the first observation period, aggressive behaviors on the part of peers were mostly unrelated to target children's peer status and behavior problem scores. At time 2, verbally aggressive peer responses to targets were slightly positively associated with peer nominations of re- 
Table VIII. Target Child Aggression at Different Time Periods in Relation to Measures of Social Maladjustment ${ }^{a}$

\begin{tabular}{lllllllll}
\hline & \multicolumn{3}{c}{ Fall } & & \multicolumn{3}{c}{ Spring } \\
\cline { 2 - 3 } \cline { 7 - 8 } & TCON & PNEG & PAGG & & TCON & PNEG & PAGG \\
\hline Time 1 & & & & & & & \\
Verbal aggr. initiations & .16 & $.25^{b}$ & $.39^{c}$ & & .04 & $.42^{c}$ & $.33^{b}$ \\
Physical aggr. initiations & .07 & .21 & .12 & & .21 & .21 & .19 \\
Verbal aggr. responses & .11 & .06 & .09 & & .02 & $.29^{b}$ & .19 \\
Physical aggr. responses & .12 & $.43^{d}$ & .20 & & .22 & $.39^{c}$ & $.29^{b}$ \\
Time 2 & & & & & & & \\
Verbal aggr. initiations & .07 & .09 & .05 & & .07 & .03 & .05 \\
Physical aggr. initiations & .18 & .07 & $.25^{b}$ & & .18 & .12 & $.34^{b}$ \\
Verbal aggr. responses & .06 & .06 & .09 & & .09 & $.32^{b}$ & $.25^{b}$ \\
Physical aggr. responses & .11 & .10 & .00 & & .06 & .05 & .12 \\
Time 3 & & & & & & & \\
Verbal aggr. initiations & .19 & .00 & .10 & & .18 & .10 & .05 \\
Physical aggr. initiations & $.36^{c}$ & $.26^{b}$ & $.41^{c}$ & & $.32^{c}$ & .13 & $.30^{b}$ \\
Verbal aggr. responses & $.31^{b}$ & .16 & $.39^{c}$ & & $.26^{b}$ & $.28^{b}$ & $.44^{c}$ \\
Physical aggr. responses & $.29^{b}$ & .17 & $.33^{b}$ & & $.29^{b}$ & .12 & $.38^{c}$ \\
\hline
\end{tabular}

$a_{\text {TCON }}=$ Conduct Problems, Conners Teacher Questionnaire; PNEG = negative peer nominations; PAGG = peer nominations of impulsive-aggressive behavior; aggr. = aggressive.

$b_{p}<.05$.

$c_{p}<.01$.

${ }_{p} p<.001$.

jection and behavioral deviance in the target children. Finally, during the third observation period, aggressive behavior on the part of peers was consistently associated with social maladjustment in target children. Children rated highly on all maladjustment scales tended to receive relatively high rates of verbally and physically aggressive initiations from peers. In addition, children who were perceived negatively by peers tended to draw higher rates of aggressive peer responses than others.

In summary, these data suggest that negative social transactions between rejected/disruptive children and their peers develop progressively over the course of time. Early in the preschool year, children who were perceived as behaviorally maladjusted by peers and teachers showed relatively high rates of aggressive initiations and responses to peers. Aggressive behaviors on the part of peers were mostly unrelated to children's social maladjustment scores during this early time period. However, by the end of the preschool year, peers made frequent verbally and physically aggressive initiations to children rated highly on all maladjustment scales, and tended to receive relatively high rates of aggressive responses from these children. 
Table IX. Peer Aggression to Target at Different Time Periods in Relation to Measures of Social Maladjustment ${ }^{a}$

\begin{tabular}{lccccccc}
\hline & \multicolumn{3}{c}{ Fall } & & \multicolumn{3}{c}{ Spring } \\
\cline { 2 - 3 } \cline { 6 - 7 } \cline { 6 - 7 } & TCON & PNEG & PAGG & & TCON & PNEG & PAGG \\
\hline Time 1 & & & & & & & \\
Verbal aggr. initiations & .16 & .02 & .04 & & .13 & .01 & .05 \\
Physical aggr. initiations & .22 & .03 & .17 & & .20 & .12 & .15 \\
Verbal aggr. responses & .02 & .02 & .07 & & .03 & $.31^{b}$ & .10 \\
Physical aggr. responses & .23 & .23 & .08 & & .10 & .18 & .00 \\
& & & & & & & \\
Time 2 & .16 & .16 & .01 & & .28 & .17 & .01 \\
Verbal aggr. initiations & .00 & .07 & .01 & & .04 & .02 & .03 \\
Physical aggr. initiations & .02 & .17 & $.34^{c}$ & & .16 & $.31^{b}$ & $.29^{b}$ \\
Verbal aggr. responses & .03 & .06 & .08 & & .06 & .02 & .06 \\
Physical aggr. responses & .03 & & & & & & \\
Time 3 & & & & & & & \\
Verbal aggr. initiations & .18 & $.30^{b}$ & $.42^{c}$ & & $.32^{b}$ & $.27^{b}$ & $.37^{c}$ \\
Physical aggr. initiations & $.29^{b}$ & $.41^{c}$ & $.49^{d}$ & & $.27^{b}$ & $.28^{b}$ & $.45^{d}$ \\
Verbal aggr. responses & .05 & .16 & .18 & & .19 & .08 & .12 \\
Physical aggr. responses & .02 & .22 & $.38^{b}$ & & .08 & $.28^{b}$ & $.25^{b}$ \\
\hline
\end{tabular}

$\overline{a^{a}}$ TCON $=$ Conduct Problems, Conners Teacher Questionnaire; PNEG = negative peer nominations; PAGG = peer nominations of impulsive-aggressive behavior; aggr. = aggressive.

$b_{p}<.05$.

$\begin{aligned} c_{p} & <.01 \\ q_{p} & <.001\end{aligned}$

\section{Analyses of Coercive-Aggressive Peer Interaction Sequences}

Previous analyses suggested that peers may become increasingly hostile to disruptive/aggressive children over the course of time. Because this finding is central to a transactional conceptualization of early social maladjustment, analyses of coercive-aggressive peer interaction sequences were undertaken to further examine temporal relationships between peer interaction and children's social maladjustment levels. In order to conduct these analyses, it was necessary to divide children into extreme (maladjusted/nonmaladjusted) groups. Peer nominations of disliking and disruptive/aggressive behavior problems were given precedence as selection criteria for extreme group designations, because they were more consistently linked to patterns of socially aversive peer interaction than were teacher ratings. Likewise, Time 2 measures were used as selection criteria, because they were assumed to be the most reliable and valid indices of children's social and behavioral status. Thus, aggressive/disliked boys $(n=$ 16) were those whose scores on the peer measures of maladjustment were $1 S D$ above the mean, and whose scores on the teacher scale of behavioral 
deviance exceeded the mean. The comparison group $(n=17)$ consisted of boys whose scores on the peer measures were $1 S D$ below the mean, and whose scores on the teacher scale were also below the mean.

For each separate observation period, the following Lag 1 sequences were identified and coded for frequency: (1) aggressive target initiation, aggressive peer response; (2) aggressive target initiation, nonaggressive peer response; (3) nonaggressive target initiation, aggressive peer response; (4) aggressive peer initiation, aggressive target response; (5) aggressive peer initiation, nonaggressive target response; and (6) nonaggressive peer initiation, aggressive target response. Repeated-measures MANOVAs were conducted for each different type of sequence, with group (aggressive/nonaggressive) as the between-subjects factor and time of observation $(1,2$, or 3$)$ as the within-subjects factor. Based on the results of previous analyses, it was hypothesized that aggressive target children would make higher levels of aggressive initiations to peers than others, and that aggressive peer initiations to maladjusted target children would increase over time. These hypotheses were generally confirmed. First, sequences involving target initiations to peers were examined. The MANOVA for sequences involving aggressive target initiations followed by aggressive counterresponses from peers did not yield significant between- or within-group differences. However, the MANOVA for sequences involving aggressive target initiations followed by nonaggressive peer responses did reveal a significant main effect for group, $F(1,32)=7.47, p<.01$. Univariate $F$-tests revealed that aggressive boys were significantly more likely than nonaggressive boys to initiate aggressive interactions that were not reciprocated by peers at Times 2 and $3(F=$ $6.49, p<.01$, and $F=4.22, p<.05$, respectively; aggressive $M=2.53$ and 2.64 , nonaggressive $M=0.60$ and 1.05 , at Times 2 and 3 , respectively). Finally, sequences involving nonaggressive target initiations followed by aggressive peer responses were examined for group and temporal differences. Although the MANOVA failed to reach significance, univariate $F$-tests revealed that aggressive boys received more "unprovoked" peer aggression at Time 3 than others $(F=5.59, p<.05$; aggressive $M=0.64$, nonaggressive $M=0.10$ ). This finding is consistent with the hypothesis that aggressive children are more likely to be victimized by peers as time progresses.

Sequences involving aggressive and nonaggressive peer initiations to target children were examined next. The MANOVA for sequences involving aggressive peer initiations followed by aggressive target responses revealed a highly significant main effect for group, $F(1,32)=18.05, p<.000$ ). Univariate $F$-tests revealed a significant Group $\times$ Time of Observation interaction $(F=6.55, p<.01)$, whereby aggressive peer initiations that were reciprocated by targets increased over time for the aggressive children ( $M$ $=0.15,0.94$, and 1.64 at Times 1 through 3 respectively), but not for the 
comparison group $(M=0.10,0.15$, and 0.23 at Times 1 through 3 , respectively). However, the MANOVA for aggressive peer initiations that were not reciprocated by targets failed to reach significance. Finally, the MANOVA for nonaggressive peer initiations that were responded to aggressively by targets revealed a significant main effect for group, $F(1,32=7.07$, $p<.01)$. Univariate $F$-tests revealed that aggressive boys tended to respond more aggressively to nonaggressive peer initiations $(M=0.76)$ than controls $(M=0.18)$ at Time $1(F=5.49, p<.05)$, but not at later time periods.

To summarize, in comparison with nonaggressive boys, aggressive/disliked boys made more frequent aggressive initiations to peers that were not reciprocated in kind. Moreover, levels of peer initiated aggression followed by counteraggression on the part of targets highly differentiated the two groups, and tended to increase over time for the aggressive/disliked boys.

\section{DISCUSSION}

The early development of conduct problems and peer rejection is a compelling issue for research, given the long-term risk potential of these problems for school-age children. In the current study, a risk sample of preschoolers was tracked over the course of the preschool year, in order to examine the progression of individual differences in early social maladjustment. Based on previous research with older children, it was hypothesized that a transactional, social systems model would best explain the initial development and subsequent stabilization of peer rejection and conduct problems in young children. This model states that children at risk for rejection enter peer groups by behaving in ways that alienate their peers. However, as time progresses, peers begin to provoke reactive aggression in these children by taunting or otherwise victimizing them. The transactional nature of these problems may lead to long-term stabilization of maladjustment in individuals, by perpetuating negative interaction sequences, excluding opportunities for learning alternative (prosocial) skills, and ultimately, by promoting internalization of negative peer perceptions and hypersensitivity to rejection.

Consistent with the proposed model, it was expected that individual differences in negative social status would remain at least moderately stable over the course of the preschool year, and would co-occur with problems of aggression and impulsivity. These hypotheses were strongly confirmed. Boys identified by classmates as disliked were also perceived to be more physically combative, cruel, distractible, and impulsive than others. Moreover, children who were rated by teachers as high in impulsive-aggressive 
problem behavior tended to be disliked and perceived as aggressive and disruptive by peers. Finally, dislike nominations received from peers were moderately stable over time, and both the peer sociometric and teacher rating measures of behavioral deviance showed high stability over the course of the preschool year. Thus, boys identified as socially maladjusted early in the preschool year were definitely at risk for continuing to have these problems.

Previous studies have shown that measures of peer rejection in preschool children are concurrently (Millich et al., 1982; Pelham \& Bender, 1982; Rubin \& Clark, 1983) and longitudinally (Ladd \& Price, 1987; Olson \& Lifgren, 1988) associated with problems of aggression and impulsivity. Moreover, Patterson, Littman, \& Bricker (1967) reported that preschool children identified as highly aggressive with peers at the beginning of the year remained so several months later. The current findings support this body of research, and extend it by showing that both indices of maladjustment can be identified fairly early in the preschool year. Clearly, the risk potential of these problems for preschool children cannot be ignored.

Further analyses defined patterns of peer interaction most closely associated with developing conduct problems and social rejection. Although a broad range of positively and negatively valenced social behaviors were examined, individual differences in social maladjustment were most consistently associated with coercive-aggressive peer exchanges. Moreover, as hypothesized, both target children and peers contributed to the maintenance of these problems. Children identified by peers as disliked and behaviorally deviant tended to make more frequent aggressive initiations to peers than others. Consistent with the findings of Dodge (1983), maladjusted target boys manifested a broad range of socially aversive peer interaction behaviors, including threats, verbal abuse, grabbing objects away from peers, irritating mannerisms, and frank physical assaults. Perhaps most importantly, peers tended to approach children perceived as disliked and disruptive by insulting, threatening, and/or physically assaulting them. Thus, these findings were wholly consistent with the proposed transactional model.

Because prior analyses were based on overall rates of observed social interaction, children's peer interaction behaviors at different points in time were also analyzed separately in relation to their social maladjustment scores. These analyses revealed that the negative interaction patterns described above were not fully "in place" early in the preschool year, but rather developed progressively over time. During the fall, boys who eventually received high peer rejection and behavioral maladjustment scores showed relatively high rates of verbally and physically aggressive initiations to peers, and tended to respond aggressively to nonaggressive peer initiations. This early aggression was not reciprocated by peers. However, by the 
end of the preschool year, children rated highly on all maladjustment scales received relatively high rates of verbally and physically aggressive initiations from peers, and responded with counteraggression.

In summary, these findings were consistent with the hypothesis that disliked children initially behave in ways which "invite" peer rejection (Dodge, 1983), in this case by verbally and physically attacking and threatening classmates. As time progresses, however, these children become the target of increased peer aggression and teasing, thus exacerbating the frequency and intensity of coercive transactions. These points are well illustrated by the behavior of C., a boy who was evaluated by teachers as highly aggressive and by peers as highly aggressive and highly disliked. The following sequences describe C.'s peer interactions during the final observation period:

C.'s first initiation was to "drive" his toy spaceship into another boy's block tower. The other boy (N.) pushed his spaceship away. C. played by himself for one minute. During the next 7 sequences, C.'s spaceship was smashed by different peers. Each time, C. protested angrily and tried to hit their toys in return. Next, C. proceeded to knock down a block tower that a girl and boy (N.) were building. $\mathrm{N}$. replied, "Don't! That's mean, C." At this point, S. (a second boy) rammed a car into C.'s ship and said "You! Next time you build something I'll wreck it." Then, a girl grabbed C.'s robot while his gaze was averted, and taunted him by saying "I didn't take your robot" while simultaneously waving the robot in his face. C. replied, shouting angrily, "Give me it!" He reached for the robot, and threatened her by balling up his first and saying quietly, "I'll kick you, I'll smack you in the...." In response to this exchange, S. slapped $C$. and threatened, "If you smack her, I'm, gonna kick you." S. then punched C. hard five times and hit C.'s knee forcefully with a toy car, while the girl taunted him by chanting "Ha, ha." When $\mathrm{C}$. tried to move away from him, S. taunted him by saying "Chicken, chicken!" C. responded by throwing a block at $S$., and $S$ started to cry. At this point $C$. retreated and began playing alone with his spaceship. However, the girl who was involved in the previous skirmish threw a block at his ship, then grabbed his robot again. C. grabbed it back, then pushed her. S. walked over to defend her, and kicked C. twice. C. threatened to hit back, and S. retreated. The same girl grabbed C.'s spaceship, and C. pushed her away. Following a mutual block throwing exchange, the girl told another boy (N.) that C. had knocked down his block tower (C. did not do this). N. punched C. hard in the back, and C. began to sob.

It is noteworthy that the majority of coercive-aggressive initiations were addressed to the target, even after he tried to retreat from social interaction. Moreover, in line with the emotionally charged, provocative quality of the peer initiations, most of the aggression on the part of $\mathrm{C}$. was reactive in nature.

\section{Implications}

The results of this study have several implications for further research. Taken as a whole, the current findings are most relevant to the stabilization 
phase of the proposed model: Clearly, both targets and peers actively contributed to the maintenance of social maladjustment in disliked and disruptive boys. The fact that stable individual differences in negative social and behavioral status could be identified in the fall suggests that these boys enter preschool peer groups with deviant and/or deficient interpersonal skills. This hypothesis was not directly tested in the present study, but could be examined in further research by assessing individual differences in social skills prior to school entry, then relating these differences to later measures of peer status and interaction (see Putallaz, 1983, for representative methodology).

The second set of implications involve methodological issues. The current analyses of peer interaction allowed for distinctions between specific social initiations and responses of peers and targets. Similarly, the longitudinal time frame was used to assess how patterns of negative social interaction developed over time. Although these methods of analyses were painstaking to execute, the more traditional technique of assessing overall rates of social interaction at one point in time would have failed to provide a picture of the transactional nature of these problematic social exchanges.

A third point concerns the origins of early social maladjustment. The current findings suggest that disliked and disruptive preschoolers enter peer systems with problematic interpersonal styles. Given the young age of the present subjects, the most likely potential antecedents are early family socialization processes and/or difficult temperament. One strong hypothesis is that antisocial behavior is learned in the home, through parental reinforcement of coercive behavior (Patterson, DeBarsyshe, \& Ramsey, 1989). For example, parents might unwittingly give in to aversive child behavior in order to avoid prolonging conflict episodes. As time progresses, family members intensify their level of coercive interaction, and there is a parallel lack of training for prosocial skills. These coercive exchanges may exemplify not only parent-child transactions, but sibling transactions as well (Patterson, 1982). Thus, longitudinal research linking early coercive family transactions to peer rejection in preschoolers would be very valuable. Moreover, since not all children in a given family are likely to be involved in coercive transactions, the role of temperament (e.g., irritability, impulsivity, activity level) as a risk factor for involvement in early coercive familial exchanges should also be examined (see Bates, 1987, for a review of research linking early temperament and behavior problems).

Finally, the current data have implications for interventions with young children at risk for social rejection. Even though negative social reputations of maladjusted preschoolers developed early and remained stable over time, peers did not begin to actively victimize these children until later in the preschool year. These data strongly indicate a need for early intervention: Can children's risk status be attenuated by interrupting coer- 
cive social initiation styles. and teaching prosocial alternatives? Furthermore, if interventions with behaviorally disruptive/rejected children are carried out later in the preschool year, it may be necessary to execute them on a systemic (i.e., peer group) level.

\section{CONCLUSION}

In conclusion, these findings strongly support the utility of a transactional conceptualization of the development of early peer rejection and conduct problems. Consistent with previous studies of school-age (Coie \& Kuperschmidt, 1983; Dodge, 1983; Shantz, 1986) and preschool children (Ladd et al., 1988), individual differences in children's behavioral styles played an important role in the maintenance of their negative peer reputations. Negative reputations became established early in the preschool year, and remained moderately to highly stable. Children contributed to their own rejection by initiating socially aversive exchanges with peers. Although peers clearly perceived these problems, they did not reciprocate the aggressive initiations at first. As time passed, however, peers began to actively victimize these children, and were responded to with counteraggression. Paralleling Asarnow's (1983) findings with school-age boys, a self-perpetuating cycle ensued whereby maladjusted preschoolers become entranched in a web of highly affectively charged, coercive interactions. Thus, echoing Patterson (1976), rejected and disruptive preschoolers are both the architects and victims of their negative social experiences.

\section{REFERENCES}

Asher, S. R., \& Dodge, K. A. (1986). Identifying children who are rejected by their peers. Developmental Psychology, 22, 444-449.

Asarnow, J. R. (1983). Children with peer adjustment problems: Sequential and nonsequential analyses of school behaviors. Journal of Consulting and Clinical Psychology, 51, 709-717.

Bates, J. E. (1987). Temperament in infancy. In J. D. Osofsky (Ed.), Handbook of infant development (2nd ed., pp. 1101-1149). New York: Wiley.

Campbell, J. D., \& Yarrow, M. R. (1961). Perceptual and behavioral correlates of social effectiveness. Sociometry, 24, 1-20.

Campbell, S. B., Breaux, A. M., Ewing, L. J., \& Szumowski, E. K. (1986). Correlates and predictors of hyperactivity and aggression: A longitudinal study of parent-referred problem preschoolers. Journal of Abnormal Child Psychology, 14, 217-234.

Carlson, C. L., Lahey, B. B., \& Neeper, R. (1984). Peer assessment of the social behaviors of accepted, rejected, and neglected children. Journal of Abnormal Child Psychology, 12, 187-198.

Cantrell, V. L., \& Prinz, R. J. (1985). Multiple predictors of rejected, neglected, and accepted children: Relations between sociometric status and behavioral characteristics. Journal of Consulting and Clinical Psychology, 53, 884-889. 
Coie, J., \& Dodge, K. A. (1983). Continuities and changes in children's social status: A five-year longitudinal study. Merril-Palmer Quarterly, 29, 261-282.

Coie, J., Kuperschmidt, J. B. (1983). A behavioral analysis of emerging social status in boys' groups. Child Development, 54, 1400-1416.

Crowther, J. H., Bond, L. A., \& Rolf, J. E. (1981). The incidence, prevalence, and severity of behavior disorders among preschool-aged children in daycare. Journal of Abnormal Child Psychology, 9, 23-42.

Cummings, E., Ianotti, R. J., \& Zahn-Waxler, C. (1989). Aggression between peers in early childhood: Individual continuity and developmental change. Child Development, 60(4), 887-895.

Dodge, K. A. (1983). Behavioral antecedents of peer social status. Child Development, 54, 1386-1399.

Dodge, K. A., \& Coie, J. D. (1987). Social-information processing factors in reactive and proactive aggression in children's groups. Joumal of Social and Personality Psychology, 53, 1146-1158.

Dodge, K. A., Murphy, R. R., \& Buchsbaum, K. (1984). The assessment of intention-cue detection skills in children: Implications for developmental psychopathology. Child Development, $55,163-173$.

Goyette, C. H., Conners, C. K., \& Ulrich, R. F. (1978). Normative data on revised parent and teachers rating scales. Journal of Abnormal Child Psychology, 6, 221-236.

Ladd, G., Price, J. M., \& Hart, C. H. (1986). Predicting preschoolers' peer status from their playground behaviors. Child Development, 59(4), 986-992.

Ladd, G. W., \& Price, J. P. (1987). Predicting children's social and school adjustment following the transition from preschool to kindergarten. Child Development, 58, 1168-1187.

Leiter, M. P. (1977). A study of reciprocity in preschool play groups. Child Development, 48, 1288-1298.

Milich, R., \& Landau, S. (1982). Socialization and peer relations in hyperactive children. In K. D. Gadow and I. Bialer (Eds.), Advances in learning and behavior disabilities. Greenwich, CT: JAI Press.

Milich, R., Landau, S., Kilby, G., \& Whitten, P. (1982). Preschool peer perceptions of the behavior of hyperactive and aggressive children. Journal of Abnormal Child Psychology, 10, 497-510.

Olson, S. L., \& Lifgren, K. (1988). Concurrent and longitudinal correlates of preschool peer sociometrics: Comparing rating scale and nomination measures. Journal of Applied Developmental Psychology, 9, 409-420.

Olweus, D. (1979). Stability of aggressive reaction patterns in males: A review. Psychological Bulletin, 86, 852-875.

Parker, J. G., \& Asher, S. A. (1987). Peer relations and later personal adjustment: Are low-accepted children at risk? Psychological Bulletin, 102, 357-389.

Patterson, G. R. (1976). The aggressive child: Victim and architect of a coersive system. In L. A. Hamerlynck, L. C. Handy, \& E. J. Mash (Eds.), Behavior modification and families. New York: Brunner/Mazel.

Patterson, G. R. (1982). Coercive family process: A social learning approach (Vol. 3). Eugene, OR: Castalia.

Patterson, G. R., DeBarsyshe, B. D., \& Ramsey, E. (1989). A developmental perspective on antisocial behavior. American Psychologist, 44(2), 329-335.

Patterson, G. R., Littman, R. A., \& Bricker, W. (1967). Assertive behavior in children: A step toward a theory of aggression. Monographs of the Society for Research in Child Development, 113(5). 113.

Pelham, W. E., \& Bender, M. E. (19882). Peer interactions of hyperactive children: Assessment and treatment. In K. D. Gadow and I. Bialer (Eds.), Advances in learning and behavior difficulties. Greenwich, CT: JAI Press.

Putallaz, M. (1983). Predicting children's sociometric status from their behaviors. Child Development, 54, 1417-1426.

Rose, S. L., Rose, S. A., \& Feldman, J. F. (1989). Stability of behavior problems in very young children. Development and Psychology, 1, 5-19. 
Rubin, K. A., \& Clark, M. L. (1983). Preschool teachers' ratings of bchavioral problems: Observational, sociometric, and social-cognitive correlates. Journal of Abnormal Child Psychology, 11, 273-286.

Rutter, M., \& Garmezy, N. (1983). Developmental psychopathology. In E. M. Hetherington (Ed.), Carmichael's manual of child psychology: Vol. 4. Social and personality development (pp. 775-912). New York: Wiley.

Shantz, D. (1986). Conflict, aggression, and peer status: An observational study. Child Development, 57, 1322-1332. 